Research Article

\title{
Investigating the Effect of Viscous Yield Dampers on Concrete Structure Performance
}

\author{
Nima Marzban iD $^{1}$ and Parisa Esmaeiltabar Nesheli ${ }^{2}$ \\ ${ }^{1}$ Department of Civil Engineering, Tabari Non-Profit Higher Education Institute, Babol, Iran \\ ${ }^{2}$ Department of Civil Engineering, Babol University of Technology, Babol, Iran \\ Correspondence should be addressed to Nima Marzban; nima.marzban@tabari.ac.ir
}

Received 30 April 2021; Revised 1 June 2021; Accepted 23 June 2021; Published 12 July 2021

Academic Editor: S. Mahdi S. Kolbadi

Copyright (c) 2021 Nima Marzban and Parisa Esmaeiltabar nesheli. This is an open access article distributed under the Creative Commons Attribution License, which permits unrestricted use, distribution, and reproduction in any medium, provided the original work is properly cited.

\begin{abstract}
Viscous dampers are one of the most effective devices in the energy consumption of the buildings. The passive hybrid system progressive applications cause each of the dampers to compensate for the weakness of the other system, thus increasing the efficiency of passive control of the structure. Speed-based viscous dampers will adjust the amount of depreciation force based on the acceleration and velocity entering the system. On the other hand, displacement-based surge dampers adjust the amount of depreciation force based on the displacement required. Therefore, considering the different performances of these two dampers, the effect of using both of them in one structure can be investigated. In this study, by combining these two dampers, the seismic behavior of concrete structures has been evaluated. To study them, 5- and 10-story structures have been designed using FE method and have been subjected to earthquake records. Historical analysis shows that the use of hybrid dampers reduces the amount of seismic input force to the structure and also the amount of floor drift is reduced due to the use of dampers and also the capacity of structures for these structures is increased. The results of the study show that the presence of dampers in the structure increases energy absorption and improves performance in the structure.
\end{abstract}

\section{Introduction}

In conventional methods, the building demonstrates earthquake resistance by using a combination of hardness and ductility as well as energy dissipation. An efficient method used to improve seismic performance and damage control in structures is the use of energy consuming systems. In this method, mechanical energy dissipation tools are placed in the structure and deplete the energy. As a result, there is no need to use the high ductility of the structure and the nonlinear behavior of the main members to deplete the input energy. One of the most important mechanical tools is the energy consumption of viscous dampers. The location of these tools and the methods of their placement in the structure have a great impact on their efficiency and effectiveness. Tsai et al. in 1998 [1], using analytical models, showed that the combination of speed-dependent and nonspeed-dependent devices in a structure is a powerful tool to increase seismic protection. They used a combination of a TPEA metal delivery device (triangular sheet energy absorbing device) as a hysterical element with a viscoelastic (VE) damper. Chen et al. in 2002 [2] used a six-span frame with four floors, and the results proved the strengths of different devices in counteracting each other's weaknesses.

Ibrahim et al. in 2009 [3] studied about the elastomeric damping material formed using VDP devices; the VPD increases the damping by increasing the displacement of the tire, and the energy absorption capacity increases as soon as the steel elements are delivered. The damper has a hyperelastic effect when it undergoes large displacement, 
increasing the stiffness by stiffening the structure during severe seismic events to prevent the structure from collapsing. Murthy in 2000 [4], studied about VHD devices including concentric steel rims which are connected to the center of the structural opening using four braces. It is a multistage device similar to the VPD device, which has a large capacity for energy loss due to the delivery of steel and the geometry of the device. Recent research into composites or composite devices has included the addition of viscous dampers to a rugged lateral system with metal dampers. The goal is to add dampers and small displacements, as well as reduce nonstructural failure and acceleration. Brunea in 2015 [5], in an analytical study of a degree of freedom, found that viscous dampers reduce the effect of metal dampers. They also found that class accelerations were likely to increase for systems with small strain stiffness ratios. In 2014, Amadio et al. [6] analytically and experimentally investigated a hybrid system using $\mathrm{PR}$ joints and viscoelastic dampers. The advantage of a PR connection is that the damage is minimal, at least to a frame instrument with a connection hysteresis cycle. Viscoelastic dampers were used in conjunction with Chevron braces. The test results showed a significant reduction in displacement demand and instrument failure. This type of system is also able to meet the performance criteria based on the performance. The analysis proved that the best performance is obtained with the lowest cost, with an attenuation ratio of $11 \%$ or less.

So far, researchers have reviewed the hybrid passive control devices mentioned above. The idea of a combined HPCD passive control system was first proposed by Justin Marshall in 2013 [7]. The original HPCD demonstrated the phased behavior and energy dissipation of the system, which has the expected properties and behavior of the system, and the finite element models demonstrated its phased behavior and energy dissipation. Seismic structure and hazard provide an exceptional tool for performancebased seismic design. Investigation of the performance of structures under lateral loads, especially earthquake loads, is of great importance. Earthquake control, conduction, and energy dissipation can be a great help in the economic design of structures being designed and built. Therefore, in a study, the performance of structures in the state with and without two-level dampers has been investigated. In this research, three frames 5, 10, and 15 with and without dampers are examined. The results of this study show that the use of two-level dampers in 5-story structures increases the capacity of the structure by $4.7 \%$ and in 10 and 15-story structures, it improves the performance of the structure by $7.72 \%$ and $8.1 \%$, respectively. In fact, the damper has been able to increase the capacity of the structure by absorbing lateral forces, and the structure, while enduring many stresses, also leaves acceptable displacement [8]. Few studies have been performed on passive control composite devices, and the combination of speed-dependent devices due to their ability to reduce small vibrations with metal or friction devices (displacement-dependent) due to their high energy absorption capacity has considerable potential for future research [9].

In this study, four concrete structures in the form of two-dimensional frames are numerically modeled. In order to evaluate them under earthquake, the shear force and drift displacement of the floors have been used, which can indicate the seismic response of the structure. Regarding the structural cover diagram, it can be said that the structural cover diagram with damper is higher than the structural cover diagram without damper [10].

\section{Material and Methods}

In this research, four concrete structures in the form of two-dimensional frames in the number of 5 and 10 floors with a floor height of 3.2 meters and a distance of openings of 6 meters are considered. The structures are once equipped with a damper and once equipped with a viscous damper and a submersible damper. It should be noted that both dampers are used simultaneously in the concrete frame [9]. After modelling, the frames are analysed and designed. Also, the position of the dampers is in the second and fifth openings, which are specified in the following figures. The view of the modeled concrete frames is given in Figure 1.

Damper-exponential and multilinear plastic nonlinear elements have been used to model the dampers for modelling viscous and yield dampers, respectively [11]. The behavioral model of these elements is shown in Figure 2. The models are subject to earthquake records and dynamic analysis. The records used are shown in Table 1 .

\section{Numerical Simulation}

In order to evaluate the samples under earthquake records, the basic shear and drift parameters of the floors have been used, which can indicate the seismic response of the structure. Figures 3-6 show the base section of 5- and 10story structures with dampers and without dampers separately and the average base section of structures under 7 earthquake records. As can be seen, with the installation of dampers, the shear base has been significantly reduced in both height levels.

Figures 7-10 show the maximum drift of classes. To determine the drift of the floors, the drift history of each floor is specified and then the maximum drift obtained from them is selected as the maximum drift. It can be seen that despite the damper, the maximum drift of the floors has also decreased. 


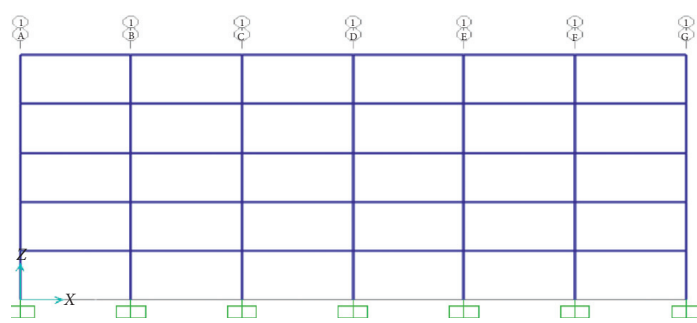

(a)

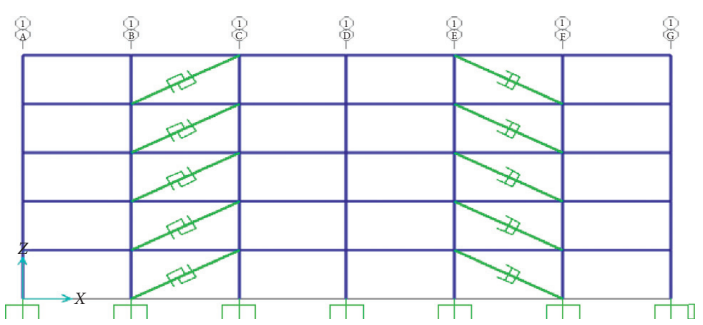

(b)

Figure 1: View of a 5-story concrete frame without and with dampers.

Hysteresis definition sketch

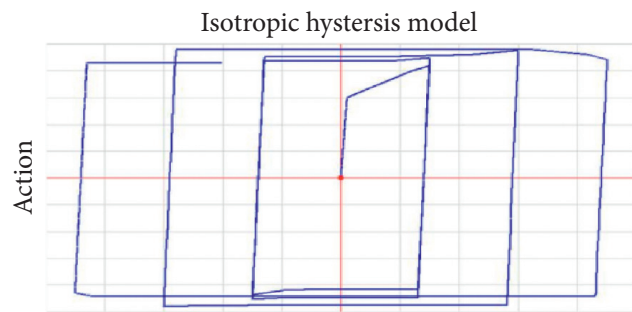

Deformation

(a)
Hysteresis definition sketch

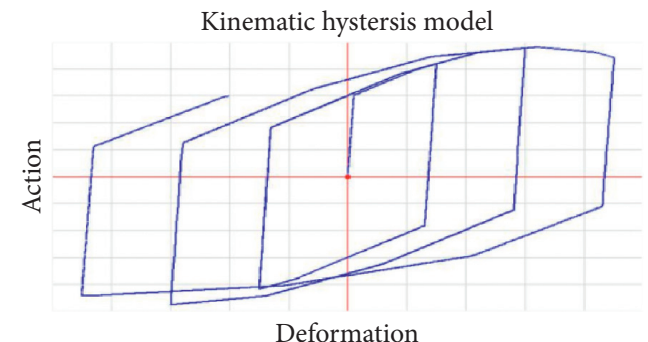

(b)

FIGURE 2: Models of nonlinear behavior of viscous and yield dampers.

TABLE 1: Characteristics of earthquakes.

\begin{tabular}{|c|c|c|c|c|c|c|}
\hline $\begin{array}{l}\text { Input time steps } \\
\text { (s) }\end{array}$ & $\begin{array}{c}\text { Maximum acceleration } \\
(\mathrm{g})\end{array}$ & $\begin{array}{c}\text { The magnitude of the } \\
\text { earthquake }\end{array}$ & $\begin{array}{c}\text { Distance from fault } \\
(\mathrm{km})\end{array}$ & Date & Earthquake & Row \\
\hline $02 / 0$ & $59 / 0$ & $1 / 7$ & $51 / 4$ & $\begin{array}{c}25 / 04 / \\
1992\end{array}$ & Ala & 1 \\
\hline $02 / 0$ & $59 / 0$ & $7 / 6$ & $71 / 4$ & $\begin{array}{c}17 / 01 / \\
1994\end{array}$ & Bam & 2 \\
\hline 0.02 & $46 / 0$ & $4 / 7$ & 19 & $\begin{array}{c}21 / 06 / \\
1990\end{array}$ & Manjil & 3 \\
\hline 0.02 & $395 / 0$ & $7 / 6$ & 11.4 & $\begin{array}{c}17 / 01 / \\
1994\end{array}$ & Northridge & 4 \\
\hline $005 / 0$ & $339 / 0$ & $5 / 6$ & $3 / 9$ & $6 / 08 / 1979$ & Imperial & 5 \\
\hline 0.005 & 0.53 & $4 / 7$ & $6 / 5$ & $\begin{array}{c}17 / 08 / \\
1999\end{array}$ & Tur & 6 \\
\hline $005 / 0$ & $452 / 0$ & $3 / 7$ & $8 / 8$ & $\begin{array}{c}15 / 06 / \\
1994\end{array}$ & Kobe & 7 \\
\hline
\end{tabular}

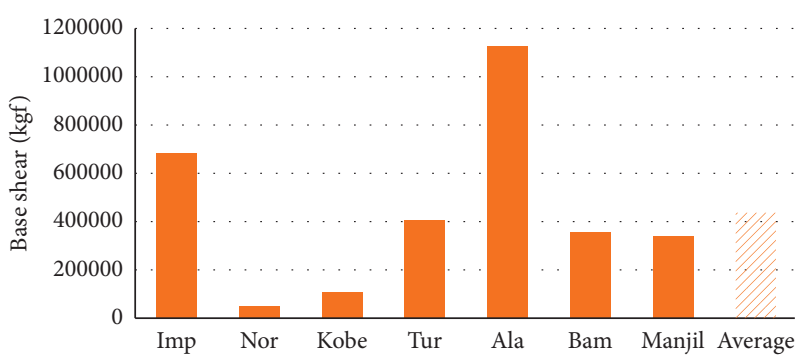

(a)

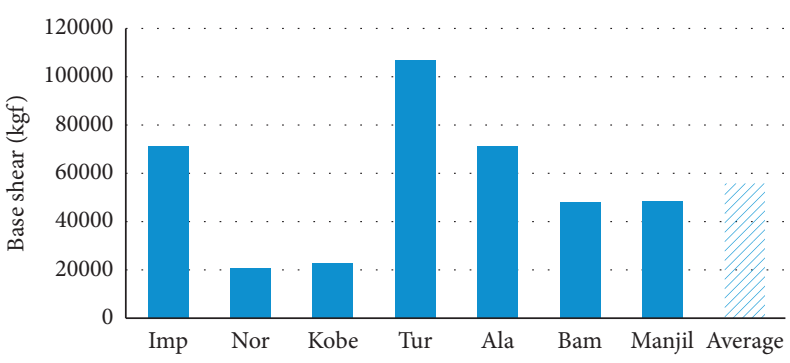

(b)

FiguRE 3: Maximum shear base diagram of a 5-story structure without and with damping. (a) Base shear without damper. (b) Base shear with damper. 


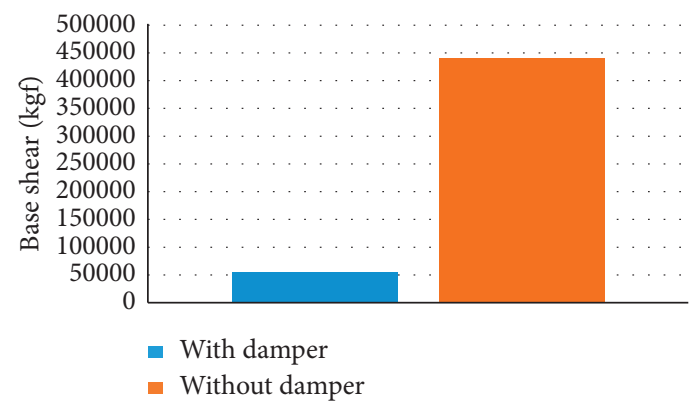

FIGURE 4: Diagram of the average shear base of the maximum of 5-story structures.

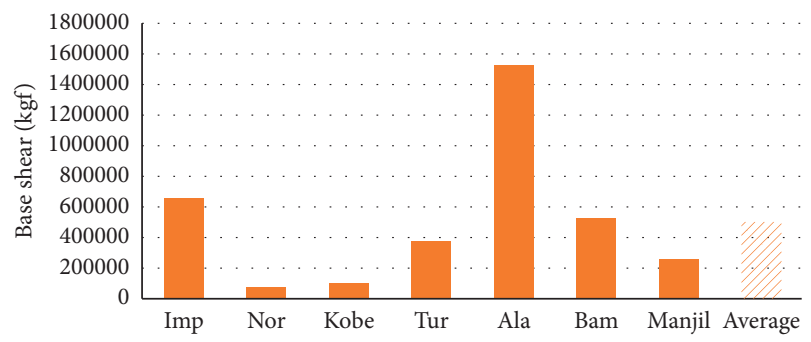

(a)

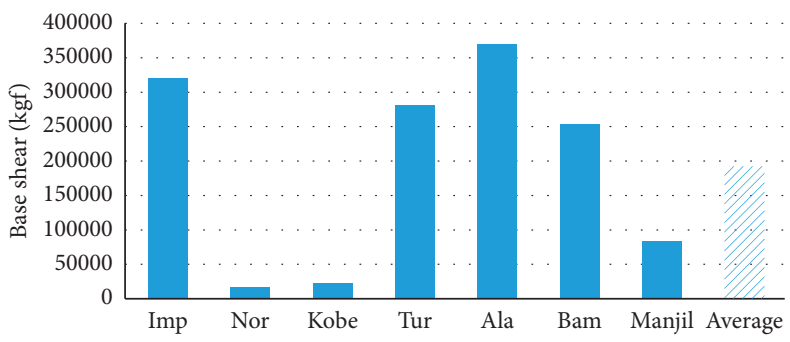

(b)

FiguRE 5: Maximum shear base diagram of a 10-story structure without and with damping. (a) Base shear without damper. (b) Base shear with damper.

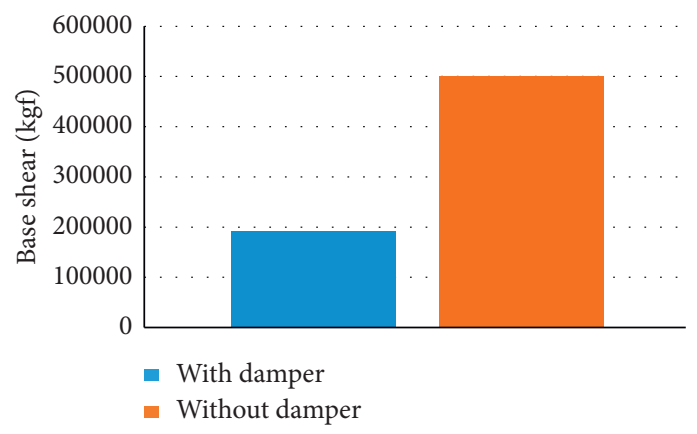

FIGURE 6: Diagram of the average shear base of the maximum of 10-story structures.

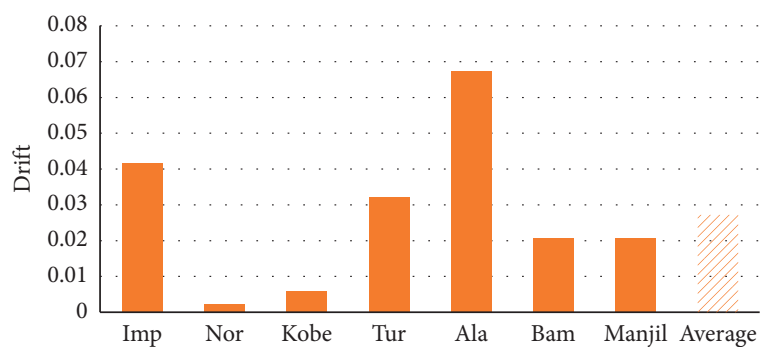

(a)

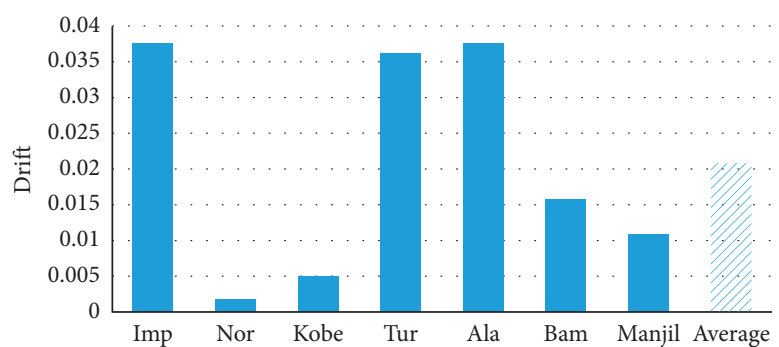

(b)

FIgURE 7: Maximum drift diagram of a 5-story structure without and with damping. (a) Drift without damper. (b) Drift with damper. 


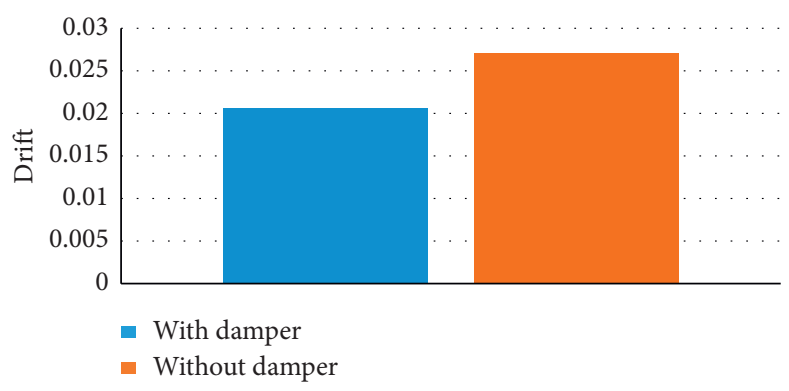

FIGURE 8: Average drift diagram of 5-story structures.

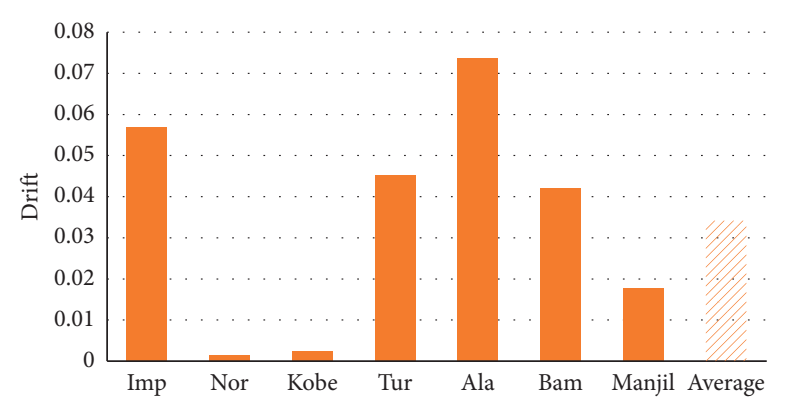

(a)

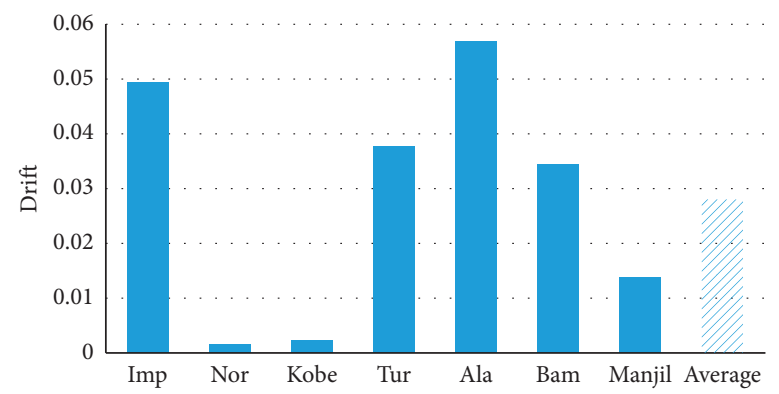

(b)

Figure 9: Diagram of the maximum drift of a 10-story structure without and with damping. (a) Drift without damper. (b) Drift with damper.

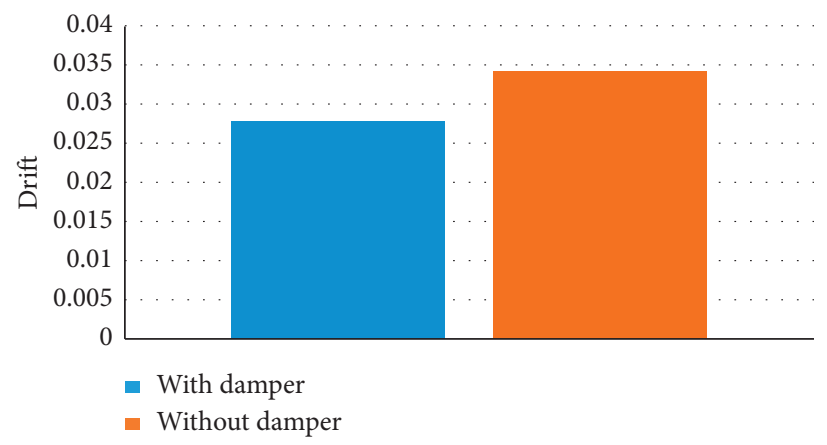

FIGURE 10: Graph of maximum drift average of 10-story structures.

\section{Conclusion}

Regarding the amount of shear base, it can be concluded that the amount of shear base of 5- and 10-story structures under the influence of dampers has decreased significantly compared to structures without dampers. According to the average values of the shear base, it can be concluded that the amount of shear base in the structure with dampers in the 5story structure is about $86 \%$ and in the 10 -story structure is about $62 \%$ compared to the structure without dampers. The maximum drift rate of 5- and 10-story structures under the influence of dampers has decreased significantly compared to structures without dampers. According to the average values of drift, it can be concluded that the maximum drift rate in the 5-story structure with dampers is about $62 \%$ and in the 10 -story structure is about $17 \%$ compared to the structure without dampers. Regarding the structural cover diagram, it can be said that the structural cover diagram with damper is higher than the structural cover diagram without damper. The presence of dampers in the structure has increased the amount of energy absorption in the 5-story structure by about $64 \%$ and in the 10-story structure by about $60 \%$, which has increased the data. Therefore, it can be concluded that the presence of dampers in the structure increases energy absorption and improves performance in the structure.

\section{Data Availability}

Requests for access to these data should be made to the corresponding author via e-mail address: nima.marzban@ tabari.ac.ir. 


\section{Conflicts of Interest}

The authors declare that there are no conflicts of interest regarding the publication of this paper.

\section{References}

[1] J. Tsai, L. Li, J. Dai, and J. Ou, "A single-degree-of-freedom system using a time-delayed control algorithm: principle and experimental study," Journal of Vibration and Control, vol. 17, pp. 1840-1850, 1998.

[2] W. Zhe, C. Liang, U. Filippo, and L. Simon, "Numerical investigation and design of reinforced concrete shear wall equipped with tuned liquid multiple columns dampers," Shock and Vibration, vol. 2021, Article ID 6610811, 19 pages, 2021.

[3] L. Chen, G. Song, and J. Ou, "A genetic algorithm-based twophase design for optimal placement of semi-active dampers for nonlinear benchmark structure," Journal of Vibration and Control, vol. 16, pp. 1379-1392, 2002.

[4] P. J. Ibrahim, S. A. Neild, and D. J. Wagg, "Semi-active damping using a hybrid control approach," Journal of Intelligent Material Systems and Structures, vol. 23, pp. 2103-2116, 2009.

[5] M. J. L. Murthy, J. V. Calvo, B. L. Boada, and V. Díaz, "Modeling of a magneto rheological damper by recursive lazy learning," International Journal of Non-linear Mechanics, vol. 46, pp. 479-485, 2000.

[6] C. Xuansheng, J. Chuansheng, and Z. Yue, "Seismic responses of an added-story frame structure with viscous dampers," Mathematical Problems in Engineering, vol. 20149 pages, Article ID 468672, 2014.

[7] C. Ho and C. K. Ma, "Active vibration control of structural systems by a combination of the linear quadratic Gaussian and input estimation approaches," Journal of Sound and Vibration, vol. 301, pp. 429-449, 2015.

[8] S. Hong, M. T. Nguyen, N. M. Kwork, Q. P. Ha, and J. Li, "Hysteresis model for magneto rheological fluid dampers using a curve fitting approach," Journal of the Japan Society of Applied Electromagnetics and Mechanics, vol. 15, pp. 176-179, 2004.

[9] D. Marshall, S. Justin, and T. Engin, "Modeling and testing of a field-controllable magneto rheological fluid damper," International Journal of Mechanical Sciences, vol. 52, pp. 1036-1046, 2013.

[10] W. Manisha, M. Suhasini, and M. Vasant, "Influence of nonlinear fluid viscous dampers on seismic response of RC elevated storage tanks," Civil engineering journal, vol. 1, pp. $12-25,2020$.

[11] W. Xiaoli, G. Wei, H. Ping, B. Dan, X. Xu, and H. Yao, "Seismic performance evaluation of building-damper system under near-fault earthquake," Shock and Vibration, vol. 2020, Article ID 2763709, 21 pages, 2020. 